\title{
BMJ Open Moderation of alcohol consumption as a recommendation in European hypertension management guidelines: a survey on awareness, screening and implementation among European physicians
}

\author{
Laila Zaidi Touis, Juliane Bolbrinker, Thomas Günther Riemer, Reinhold Kreutz
}

To cite: Zaidi Touis $L$, Bolbrinker J, Riemer TG, et al. Moderation of alcohol consumption as a recommendation in European hypertension management guidelines: a survey on awareness, screening and implementation among European physicians. BMJ Open 2018:8:e022026. doi:10.1136/ bmjopen-2018-022026

- Prepublication history and additional material for this paper are available online. To view these files, please visit the journal online (http://dx.doi. org/10.1136/bmjopen-2018022026).

Received 15 February 2018 Revised 18 July 2018 Accepted 22 August 2018

\section{Check for updates}

(c) Author(s) (or their employer(s)) 2018. Re-use permitted under CC BY-NC. No commercial re-use. See rights and permissions. Published by BMJ.

Charité - Universitätsmedizin Berlin, Corporate Member of Freie Universität Berlin, Humboldt-Universität zu Berlin, and Berlin Institute of Health, Institut fur Klinische Pharmakologie und Toxikologie, Berlin, Germany

Correspondence to Laila Zaidi Touis; laila.zaidi-touis@charite.de

\section{ABSTRACT}

Objectives Moderation of alcohol consumption is included as a class I, level of evidence A recommendation in the current European guidelines for the management of hypertension. We investigated its awareness and selfreported implementation among European physicians across different specialties and workplaces.

Design and setting A cross-sectional survey study conducted in two annual German meetings (German Society of Cardiology and the German Society of Internal Medicine) and two annual European meetings (European Society of Hypertension and European Society Cardiology) in 2015 .

Participants 1064 physicians attending the European meetings were interviewed including $52.1 \%$ cardiologists, $29.2 \%$ internists and $8.8 \%$ general practitioners.

Main outcome measures Physician screening of alcohol consumption, awareness and self-implementation of the recommendation of the current European guidelines about moderation of alcohol consumption for the management of hypertension.

Results Overall, $81.9 \%$ of physicians reported to generally quantify alcohol consumption in patients with hypertension. However, only $28.6 \%$ and $14.5 \%$ of participants reported screening alcohol consumption in their patients with newly detected or treatment-resistant hypertension. Physicians recommended a maximum alcohol intake of $13.1 \pm 11.7 \mathrm{~g} /$ day for women $(95 \% \mathrm{Cl}$ 12.3 to 13.8$)$ and $19.9 \pm 15.6 \mathrm{~g} /$ day for men $(95 \% \mathrm{Cl}$ 18.8 to 20.9). In case of moderate to high alcohol consumption, $10.3 \%$ would manage only hypertension without addressing alcohol consumption, while $3.7 \%$ of the physicians would do so in case of alcohol dependence $(p<0.001)$.

Conclusions The average amount of alcohol intake per day recommended by European physicians in this survey was in agreement with the guidelines. The low number of physicians that screen for alcohol consumption in patients with newly detected and with treatmentresistant hypertension indicates an important deficit in the management of hypertension.
Strengths and limitations of this study

- Identifying deficits in the management of alcohol consumption among European physicians attending annual scientific meetings in the field of cardiovascular or internal medicine indicates a need to develop better future alcohol interventions.

- The majority of physicians participating in this survey were hospital based $(78.5 \%)$, although outpatient care in the ambulatory setting plays a predominate role in the long-term management of hypertension.

- Answers were self-reported in a face-to-face interview, which might have shifted some results upwards and led to an overestimation in our analysis.

\section{INTRODUCTION}

High blood pressure (BP) or hypertension represents a main non-communicable risk factor for global burden of disease. ${ }^{1}$ In 2015 , the global age-standardised prevalence of raised $\mathrm{BP}$ was $24.1 \%$ in men and $20.1 \%$ in women, ${ }^{2}$ affecting more than one billion subjects worldwide ${ }^{3}$ and thus constituting a primary health concern. ${ }^{3}$ The harmful use of alcohol accounts for $5.1 \%$ of the global burden of disease and injury, measured in disability-adjusted life years, ${ }^{5}$ and for 3.3 million deaths every year, representing $5.9 \%$ of all deaths worldwide. ${ }^{5}$ Among the more than 200 diseases and injuries for which alcohol causality is well established, ${ }^{6}$ we also find a linear relationship between elevated BP and alcohol consumption. ${ }^{78}$ The exact mechanism of alcohol-induced hypertension is complex ${ }^{9}$ and on a molecular level still largely unknown. ${ }^{9}$ On one hand, alcohol seems to increases the tendency to vasoconstriction due to an impairment of the baroreceptors ${ }^{10} 11$ and imbalance of the 
central nervous system regulation, resulting in enhanced sympathetic activity. ${ }^{12}$ In addition, alcohol consumption increases also cortisol levels and stimulates the reninangiotensin-aldosterone system. ${ }^{13}$ The chronic alcohol-induced elevation of angiotensin II has been shown in rodents to directly cause inflammation and endothelial injury through increase of oxidative stress. ${ }^{1415}$ This, on the other hand, leads to inhibition of endothelium-dependent nitric oxide production and thus to endothelial dysfunction with impaired vasodilation. ${ }^{16} 17$

Accordingly, moderation of alcohol consumption to no more than $20-30 \mathrm{~g}$ of alcohol per day in men and $10-20 \mathrm{~g}$ of alcohol per day in women was one of the six recommended lifestyle changes in the current European Society of Hypertension (ESH) and European Society of Cardiology (ESC) guidelines for the management of arterial hypertension ${ }^{18}$ (online supplementary table 1 ). While not done in the previous edition in 2007 and its reappraisal in 2009, the last available guidelines (2013) graded the strength of this six recommended lifestyle changes for the first time with a class I evidence level A.

Currently, BP control rates in patients treated with hypertension across Europe are insufficient, with less than $50 \%$ of the patients achieving BP goals, ${ }^{19-21}$ and alcohol seems to be the least intervened factor in the management of hypertension. ${ }^{22-24}$ According to the latest WHO status report on alcohol and health, ${ }^{6}$ the amount of alcohol consumed in the European Region is almost twice the worlds average. ${ }^{6}$ Thus, efforts aiming to improve BP control, specifically through interventions in the management of alcohol consumption, are justified. Furthermore, the impact of screening and brief interventions for alcohol use in primary care have been proven positive in many European projects, ${ }^{25}{ }^{26}$ such as the Primary Health care European Project on $\mathrm{Alcohol}^{27}$ and the Optimizing Delivery of Health care Interventions. ${ }^{28} 29$

Against this background, we conducted a survey to investigate, by European physicians across different specialties and workplaces, screening of alcohol consumption, awareness and self-implementation of the recommendation to moderate alcohol consumption in their patients with hypertension.

\section{METHODS}

The survey collected data during four annual congresses between April and October 2015. Two of the meetings were German (meeting of the German Society of Cardiology (DGK) ${ }^{30}$ and the German Society of Internal Medicine $\left.(\mathrm{DGIM})^{31}\right)$, and two were European $\left(\mathrm{ESH}^{32}\right.$ and ESC). ${ }^{33}$ Attending physicians willing to participate were interviewed in German in the two German meetings and in English at the two European meetings. The complete questionnaire consisted of two parts: the first containing 10 (online supplementary table 2) and the second 6 questions (table 1), respectively. Basic demographic data of

\begin{tabular}{|c|c|c|}
\hline Items & Topic & Answers \\
\hline Q11 & $\begin{array}{l}\text { Do you quantify alcohol consumption in your } \\
\text { patients with hypertension? }\end{array}$ & Yes/no \\
\hline Q12 & $\begin{array}{l}\text { When do you ask for alcohol consumption in } \\
\text { patients with hypertension? (multiple answers } \\
\text { possible) }\end{array}$ & $\begin{array}{l}\text { In patients with newly detected hypertension. } \\
\text { In patients with hypertension and very high pressure. } \\
\text { In patients with treatment-resistant hypertension. } \\
\text { Other: Please specify (free-text answers were sorted among } \\
\text { others in categories like 'Rarely-never'/ 'Always-regularly' for } \\
\text { further analysis). }\end{array}$ \\
\hline Q13 & $\begin{array}{l}\text { What actions will you take when you diagnose } \\
\text { someone with hypertension and moderate or high } \\
\text { alcohol consumption? (no alcohol dependence: } \\
\text { asked in the next question) }\end{array}$ & $\begin{array}{l}\text { Manage and treat both problems yourself. } \\
\text { Manage only hypertension. } \\
\text { Manage only hypertension and refer to a general practitioner for } \\
\text { the management of alcohol problems. } \\
\text { Manage only hypertension and refer to specialist care for alcohol } \\
\text { problems. } \\
\text { Other (specify). }\end{array}$ \\
\hline Q14 & $\begin{array}{l}\text { What actions will you take when you diagnose } \\
\text { someone with both alcohol dependence and } \\
\text { hypertension? }\end{array}$ & $\begin{array}{l}\text { Manage and treat both problems yourself. } \\
\text { Manage only hypertension and refer to a general practitioner for } \\
\text { management alcohol problems. } \\
\text { Manage only hypertension and refer to specialist care for alcohol } \\
\text { problems. } \\
\text { Other (specify). }\end{array}$ \\
\hline Q15 & $\begin{array}{l}\text { Which maximum amount of alcohol in g/day } \\
\text { do you advise your female/male patients with } \\
\text { hypertension? }\end{array}$ & Insert number, spontaneously answered. \\
\hline Q16 & $\begin{array}{l}\text { How many of your hypertension patients have } \\
\text { additional alcohol problems (in \%)? }\end{array}$ & Insert number, spontaneously answered. \\
\hline
\end{tabular}


the participants as well as awareness and implementation of the six recommended life style changes in the 2013 $\mathrm{ESH} / \mathrm{ESC}$ guidelines ${ }^{18}$ into clinical practice were assessed through part 1 (online supplementary table 2); the results are reported elsewhere. ${ }^{34}$ Part 2 of the survey included six questions (table 1), which focused exclusively on the awareness and implementation of the European physicians regarding the role of moderation of alcohol intake in the management of their patients with hypertension.

Throughout the manuscript, we expressed all measures using consistently grams of alcohol to report amounts of ethyl alcohol (ethanol). According to the UK Chief Medical Officers, ${ }^{35}$ a unit of alcohol contains $8 \mathrm{~g}$ of pure alcohol. ${ }^{35}$

\section{Patient and public involvement}

No patients were involved in this study.

\section{Statistical analysis}

Data were analysed with SPSS software (IBM SPSS Statistics V.24). The number of responses available for each questionnaire item is reported, and relative frequencies are given as adjusted percentages excluding missing values. For each variable of interest comparisons within the following subgroup categories were performed: meeting (European: ESH/ESC vs German: DGK/DGIM), place of work (hospital vs practice), medical specialisation (general practitioner (GP) vs cardiologists vs internists vs other specialisations). For comparison between categorical variables, $\chi^{2}$ test analyses were performed. For continuous variables, t-tests or one-way analyses of variance (with Bonferroni post hoc correction for multiple comparisons) were applied. A two-sided $\mathrm{p}<0.05$ was considered statistically significant.

\section{RESULTS}

The characteristics of the participating physicians are given in table 2. Overall, 1064 physicians (37.4\% female) took part in the survey (806 at the European and 258 at the German meetings, respectively). About $20 \%$ of the asked physicians were not willing to participate in the survey. The participants were predominantly cardiologists $(52.1 \%)$ and internists $(29.2 \%)$, while $8.8 \%$ were GPs and $78.5 \%$ of all physicians were hospital-based.

\section{Estimating proportion of patients with hypertension with additional alcohol problems}

Participating physicians $(\mathrm{n}=946)$ estimated that $18.0 \% \pm 15.9 \%$ (range: $0 \%-95 \%$ ) of their patients with hypertension have additional alcohol problems. Higher percentages were estimated by physicians attending the German meetings compared with their colleagues attending the European meetings (22.3\% vs $16.8 \%$; $\mathrm{p}<0.001)$. By their own estimates, physicians working in a practice reported that significantly higher rates of patients with hypertension have additional alcohol problems compared with their hospital-based colleagues (estimated $21.4 \%$ patients visiting a practice have additional alcohol problems vs estimated $17.2 \%$ in hospital; $\mathrm{p}<0.05)$. Concerning different medical specialisations, GPs estimated that a significantly higher percentage of their patients with hypertension $(27 \%, \mathrm{p}<0.001)$ are affected by additional alcohol problems compared with cardiologists $(16.7 \%)$, internists $(18.4 \%)$ or physicians from other specialisations (16.9\%).

\section{Quantification of alcohol consumption}

Overall, $81.9 \%$ of participating physicians $(\mathrm{n}=1028)$ responded 'yes' to the question 'Do you quantify alcohol consumption in your patients with hypertension?' (Q11, table 1). Physicians attending the German meetings quantified the alcohol consumption of their patients with hypertension significantly less often than the attendees of the European meetings ( $74.5 \%$ vs $84.3 \%$; $\mathrm{p}<0.001$ ). The frequencies for quantification of alcohol consumption did not show any statistically significant association according to place of work or specialisation of physicians (data not shown).

Screening of alcohol consumption in different clinical settings In the survey, 986 physicians responded to the question 'When do you ask for alcohol consumption in patients with hypertension?' (figure 1A). Screening of alcohol consumption took place primarily in the context of newly detected hypertension (28.6\%) rather than in patients with hypertension and very high BP $(17.5 \%)$ or in patients with treatment-resistant hypertension $(14.5 \%)$. Free-text answers were additionally sorted and classified into 'Rarely-never' and 'Always-regularly'. Overall, 55.2\% of the respondent physicians reported regularly quantifying alcohol consumption in their patients with hypertension. When responses of the attendees at the European and German meetings were compared, significantly more physicians attending the European meetings reported asking about alcohol consumption in their patients with hypertension regularly ( $68.8 \%$ vs $10.8 \%$; $\mathrm{p}<0.001$; figure 1A).

GPs asked significantly more often $(42.5 \%)$ than internists $(28.2 \%)$, cardiologists $(26.8 \%)$ or physicians from other medical specialisations $(25.8 \%$; all $\mathrm{p}<0.05)$ about alcohol consumption in patients with newly detected hypertension. Similar differences between GPs and physicians from other specialties were observed regarding screening of alcohol consumption in patients with very high $\mathrm{BP}$ as well as in patients with treatment-resistant hypertension (figure 1B).

\section{Self-reported management or referral of patients with hypertension for the treatment of hypertension and/or alcohol problems}

In patients with both hypertension and moderate to high alcohol consumption, $52 \%$ of the responding physicians $(n=1021)$ would treat and manage both conditions by themselves and $10.3 \%$ would manage only hypertension without taking further action. In case of alcohol 
Table 2 Characteristics of participating physicians

\begin{tabular}{|c|c|c|c|}
\hline & All meetings $n=1064$ & $\begin{array}{l}\text { European meetings } \\
\text { ESC/ESH 2015 } \\
n=806(75.8 \%)\end{array}$ & $\begin{array}{l}\text { German meetings } \\
\text { DGIM/DGK 2015 } \\
n=258(24.2 \%)\end{array}$ \\
\hline \multicolumn{4}{|l|}{ Sex } \\
\hline Women & 396 (37.4\%) & $281(35.0 \%)$ & $115(44.6 \%)$ \\
\hline Men & $664(62.6 \%)$ & $521(65.0 \%)$ & $143(55.4 \%)$ \\
\hline Missing data & 4 & 4 & 0 \\
\hline \multicolumn{4}{|l|}{ Age category } \\
\hline 20-29years & $89(8.4 \%)$ & $76(9.5 \%)$ & $13(5 \%)$ \\
\hline 30-39 & $261(24.6 \%)$ & $205(25.6 \%)$ & $56(21.7 \%)$ \\
\hline $40-49$ & $310(29.3 \%)$ & $235(29.3 \%)$ & $75(29.1 \%)$ \\
\hline $50-59$ & $274(25.9 \%)$ & $196(24.5 \%)$ & $78(30.2 \%)$ \\
\hline 60 years or older & 125 (11.8\%) & 89 (11.1\%) & 36 (13.9\%) \\
\hline Missing data & 5 & 5 & 0 \\
\hline \multicolumn{4}{|l|}{ Nationality } \\
\hline European countries & $1004(94.8 \%)$ & $746(93.1 \%)$ & $258(100 \%)$ \\
\hline Non-European countries & $55(5.2 \%)$ & $55(6.9 \%)$ & 0 \\
\hline Missing data & 5 & 5 & 0 \\
\hline \multicolumn{4}{|l|}{ Place of work } \\
\hline Practice & $226(21.5 \%)$ & $130(16.4 \%)$ & $96(37.4 \%)$ \\
\hline Hospital & 824 (78.5\%) & $663(83.6 \%)$ & $161(62.6 \%)$ \\
\hline Missing data & 14 & 13 & 1 \\
\hline \multicolumn{4}{|l|}{ Specialisation } \\
\hline General practitioner & $93(8.8 \%)$ & $81(10.1 \%)$ & $12(4.7 \%)$ \\
\hline Cardiologist & $551(52.1 \%)$ & $443(55.3 \%)$ & $108(42.2 \%)$ \\
\hline Internist & $308(29.1 \%)$ & $200(25.0 \%)$ & $108(42.2 \%)$ \\
\hline Other specialisation & $105(9.9 \%)$ & 77 (9.6\%) & $28(10.9 \%)$ \\
\hline Missing data & 7 & 5 & 2 \\
\hline \multicolumn{4}{|l|}{ Membership } \\
\hline ESH and/or ESC & $494(60.4 \%)$ & $494(87.9 \%)$ & NA \\
\hline Membership in the DHL & $24(2.9 \%)$ & NA & $24(9.4 \%)$ \\
\hline $\begin{array}{l}\text { No ESH/ESC or DHL } \\
\text { membership }\end{array}$ & $300(36.7 \%)$ & $68(12.1 \%)$ & $232(90.6 \%)$ \\
\hline Membership total & $518(63.3 \%)$ & NA & NA \\
\hline Missing data & 246 & NA & 2 \\
\hline
\end{tabular}

Numbers and percentages refer to total responses available for each item; relative frequencies are reported as adjusted percentages excluding missing values.

DGIM, German Society of Internal Medicine; DGK, German Society of Cardiology; DHL, German Society of Hypertension; ESC, European Society of Cardiology; ESH, European Society of Hypertension; NA, not applicable.

dependence, $13.8 \%$ would treat both hypertension and alcohol dependence, while $3.7 \%$ would treat only hypertension without taking further action, and $64.1 \%$ would only treat hypertension and refer the patient to a specialist for the management of alcohol dependence $(p<0.001)$. These differences are shown in figure 2.

In patients with moderate or high alcohol consumption but without alcohol dependence, $58.9 \%$ of the internists reported managing both hypertension and alcohol problems significantly more as compared with cardiologists
$(49.2 \%)$ and other specialists $(44 \%$; $<<0.001)$. Differences between internists and GPs were not statistically significant ( $58.9 \%$ vs $52.8 \% ; p>0.05)$. In addition, physicians working in a practice were significantly more likely to manage both hypertension and the alcohol problems themselves, than their colleagues working in a hospital $(59.1 \%$ vs $50.3 \%$; $\mathrm{p}<0.05)$. Physicians attending the German meetings reported managing both alcohol dependence and hypertension significantly more than their colleagues attending the European meetings ( $14.7 \%$ vs $10.9 \%$; $\mathrm{p}<0.001)$. 

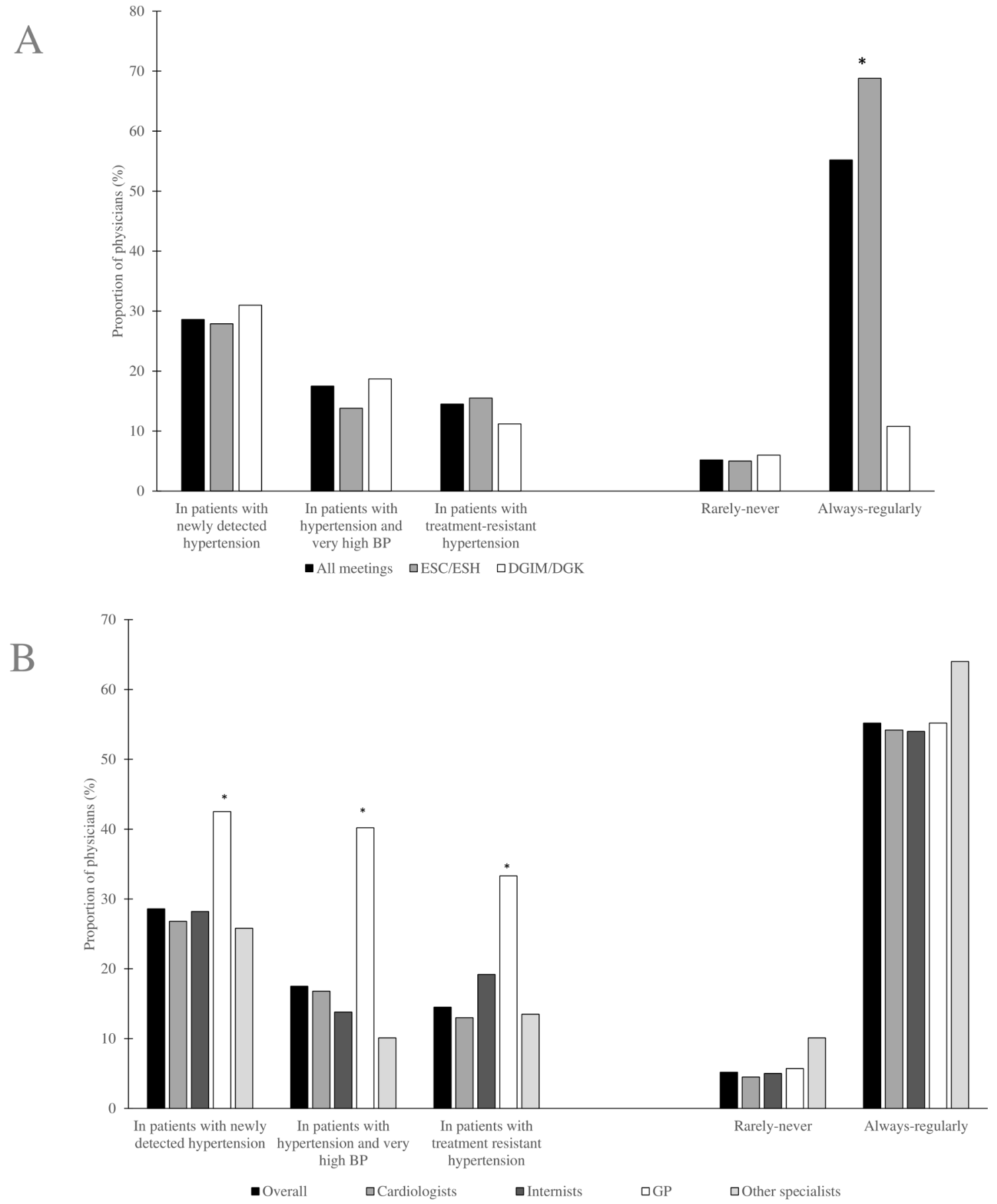

Figure 1 Proportion of physicians (\%) answering the multiple choice question: 'When do you ask for alcohol consumption in patients with hypertension?' (A) Proportion of physicians (all meetings $n=986$ ) attending the European meetings compared with the physicians attending the German meetings. Differences are significant ${ }^{*} \mathrm{p}<0.05$. (B) Proportion of physicians from different medical specialties (overall $n=981$ ); ${ }^{*}$ Difference is significant $p<0.05$ for GP compared with each one of the other specialisations. BP, blood pressure; DGIM, German Society of Internal Medicine; DGK, German Society of Cardiology; ESC, European Society of Cardiology; ESH, European Society of Hypertension; GP, general practitioner.

\section{Maximum amount of alcohol per day recommended}

Physicians reported to recommend a maximum alcohol intake of $13.1 \pm 11.7 \mathrm{~g} /$ day for women $(\mathrm{n}=901$ reporting physicians; $95 \%$ CI 12.3 to 13.8 ; range: $0-150$ ) and $19.9 \pm 15.6 \mathrm{~g} /$ day for men $(\mathrm{n}=884$ reporting physicians; 95\% CI 18.8 to 20.9 ; range: $0-150$ ).
For men, $43 \%$ of physicians recommended less than $20 \mathrm{~g}$ alcohol intake/day, $44 \%$ recommended between 20 and $30 \mathrm{~g} /$ day and $13 \%$ recommended more than $30 \mathrm{~g} /$ day. In their recommendations for women, $21 \%$ recommended less than $10 \mathrm{~g} /$ day, $71 \%$ recommended $10-20 \mathrm{~g} /$ day women and $8 \%$ recommended more than $20 \mathrm{~g} /$ day women. 


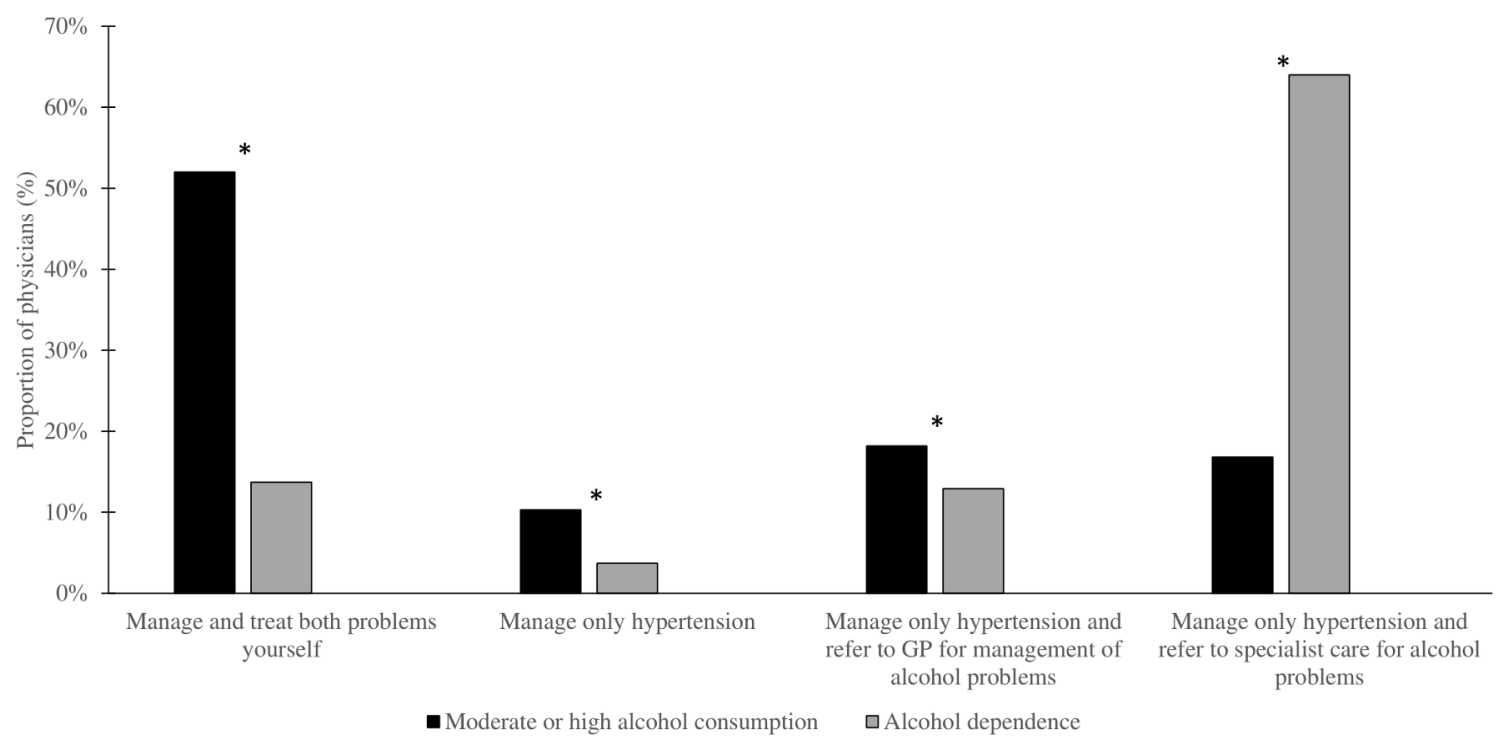

Figure 2 Proportion of physicians (\%) answering the multiple choice question: 'What actions will you take when you diagnose someone with hypertension and alcohol consumption?' Differences are significant ${ }^{*} \mathrm{p} \leq 0.001$ in case of moderate and high alcohol consumption ( $n=1021$, physicians) versus alcohol dependence ( $n=1025$, physicians). GP, general practitioner.

Physicians attending the German meetings were significantly more tolerant with their recommendations of the maximum amount of alcohol per day for women and men than their colleagues attending the European meetings $(15.8 \pm 9.4 \mathrm{~g} /$ day vs $12.1 \pm 12.2 \mathrm{~g} /$ day for women and $28.3 \pm 17.5 \mathrm{~g} /$ day vs $16.9 \pm 13.7 \mathrm{~g} /$ day for men; $\mathrm{p}<0.001$ ). Physicians working in a practice were consistently more tolerant than hospital-based physicians in their recommended maximum alcohol intake for men $(23.5 \pm 20.8 \mathrm{~g} /$ day vs $18.8 \pm 13.6 \mathrm{~g} /$ day; $\mathrm{p}<0.05$ ), but not for women $(14.7 \pm 15.0 \mathrm{~g} /$ day vs $12.6 \pm 10.5 \mathrm{~g} /$ day; $\mathrm{p}>0.05)$. Significant differences were not observed for the alcohol intake of men or women between physicians belonging to different medical specialisations (table 3 ).

\section{DISCUSSION}

The relationship between elevated $\mathrm{BP}$ and alcohol consumption is well established, ${ }^{78}$ and the importance of their burden of diseases, ${ }^{1-6} 36$ prove them as global public health priorities. Consequently, alcohol consumption and raised $\mathrm{BP}$ are key parts of $\mathrm{WHO}$ goals to reduce non-communicable diseases (NCD) global NCD mortality by $25 \%$ by $2025 .{ }^{6}$

According to a review and meta-analysis by Roerecke et $a l^{8}{ }^{8}$ moderation of alcohol consumption can reduce BP in a dose-dependent manner in people drinking more than $24 \mathrm{~g}$ of pure alcohol per day. ${ }^{8}$ Furthermore, this reduction was shown to be similar to that of other lifestyle changes, ${ }^{8}$ such as regular exercise ${ }^{37}$ or reduction of weight. ${ }^{38}$ Lifestyle changes can reduce or eliminate the need for antihypertensive medication in patients with hypertension, ${ }^{39-41}$ and their BP-lowering effects can be comparable to those effects achieved by drug monotherapy. ${ }^{3940}$ Nevertheless, even if elevated BP and harmful alcohol consumption are preventable public health priorities, until the last 15 years, alcohol policies were largely not supported by sufficient research findings. ${ }^{42} 43$ Recently, globally important public health organisations such as Global Alcohol Policy Alliance ${ }^{44}$ supported the generation of evidence-based recommendations on alcohol policies. ${ }^{44}$ In Europe, Alcohol Measures for Public Health Research Alliance (AMPHORA) ${ }^{45}$ was the first research project on alcohol from a public health perspective that had been cofinanced by the European Commission through the Seventh Framework Programme of Research. ${ }^{46}$ AMPHORA's affiliated organisations from all 27 member states aimed to generate scientific evidence about alcohol consumption and alcohol-related harm to help cover the European policy gap. ${ }^{45}$ In its final report updated in August 2013, AMPHORA reported that there is still a lot to be done and emphasised the need to identify more clearly which factors on a European level are limiting the effectiveness and implementation of alcohol policies. ${ }^{47}$ Therefore, our efforts assessing the awareness, screening and current interventions in alcohol consumption in patients with hypertension among European physicians are very well justified.

Our analysis showed that European physicians also recognised a high prevalence of high $\mathrm{BP}$ and comorbid alcoholism. About 27\% of the patients with hypertension have additional alcohol problems, as estimated by their treating physicians. Similarly, in the general population aged 15-64 years, 300 of 1000 men consume $40 \mathrm{~g}$ of alcohol or more per day in Europe. ${ }^{48}$ Some aspects and practices on the management of alcohol in patients with hypertension observed in the current survey appear acceptable or positive. These include the amount of alcohol recommended by the participating physicians for both genders, which was below the thresholds recommended in the European guidelines. ${ }^{18}$ In addition, more 
Table 3 Recommendation for alcohol intake of participating physicians

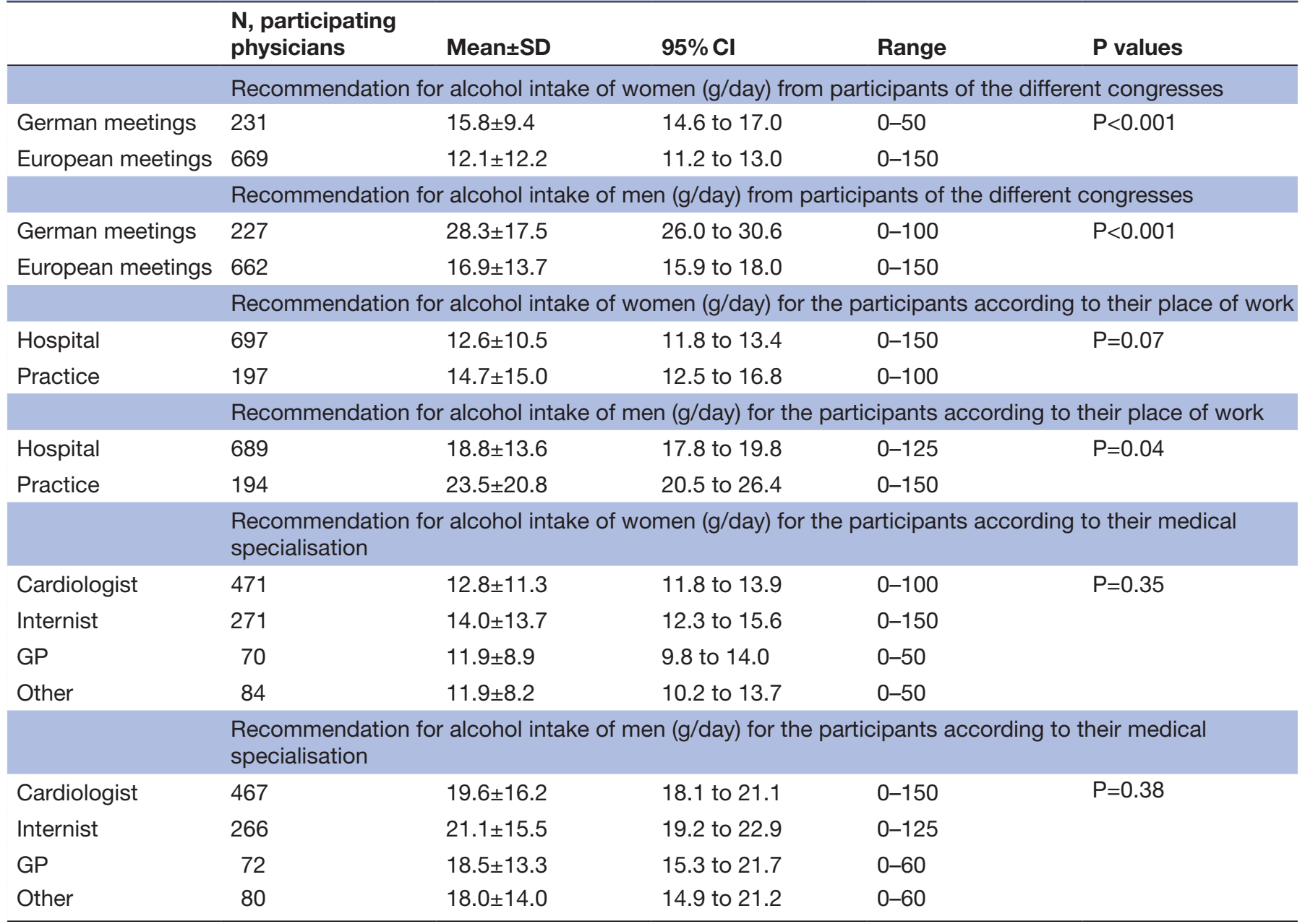

GP, general practitioner.

than $80 \%$ of the physicians reported to generally quantify the alcohol consumption of their patients with hypertension. The screening of alcohol consumption was, however, very poor in some important clinical settings. Less than one-third of the European physicians asked about alcohol consumption in cases of newly detected hypertension and less than one-fifth asked in patients with very high BP. Moreover, even fewer (14.5\% of the participating physicians) asked patients with treatment-resistant hypertension about alcohol consumption. This result is of major clinical interest, because $10 \%-30 \%$ of patients with hypertension are considered to be resistant to treatment, ${ }^{49} 50$ and patients with treatment-resistant hypertension have a considerably higher risk for stroke, cardiovascular and kidney disease than patients with controlled hypertension, as shown in multiple studies. ${ }^{51-54}$ Furthermore, there is good evidence that treatment-resistant hypertension can also be linked to non-adherence to moderation of alcohol consumption. ${ }^{55-57}$ Regarding the low number of physicians asking about alcohol consumption in newly detected hypertension, in patients with very high $\mathrm{BP}$ and in patients with treatment resistance observed in our current study, we cannot exclude the possibility that some physicians assumed that answering 'regularly' in our survey did include all of the situations mentioned above, although this question was read in the interview as a multiple choice question with the possibility of more than one answer (Q12 in figure 1). Moreover, even considering this possibility, only half of the interviewed physicians, and also half of the GPs answered 'regularly' to the question: 'When do you ask about alcohol consumption in patients with hypertension?' These percentages of alcohol screening are still unsatisfactory.

In comparison to a similar study conducted exclusively in GPs in Europe, Rehm et $a l^{22}$ noted that $34 \%$ of interviewed GPs reported sufficient screening of alcohol in patients with hypertension. However, the study design and questions are not fully comparable with the present report: The study by Rehm et al, ${ }^{22}$ was based on online questionnaires, and the interviewers did not ask if GPs quantified alcohol consumption in their hypertensive patients (yes/no). Instead, sufficient screening was assumed if GPs screened at least 7 out of 10 hypertensive patients for alcohol consumption. ${ }^{22}$ In another part of the same study, published separately by Kraus et $a l^{58}$ less than half of the German and European patients with 
hypertension in primary care were screened for alcohol use. ${ }^{58}$ Collectively, the findings by Rehm et $a l^{22}$ and Kraus et $a \hat{l}^{58}$ are in agreement with our analysis concluding that screening for alcohol consumption in hypertensive patients is poor among German and European GPs and should be improved.

In the current survey, a significantly greater fraction of physicians participating in the German meetings estimated that their patients exhibit both hypertension and alcohol problems compared with the participants at the European meetings. Nevertheless, a significantly greater fraction of physicians attending the German meetings $(25.5 \%)$ did not quantify alcohol consumption in their patients with hypertension as compared with their colleagues attending the European meetings (15.7\%). Accordingly, physicians attending the German meetings had lower awareness of the class I level of evidence A recommendation on the moderation of alcohol consumption contained in the $\mathrm{ESH} / \mathrm{ESC}$ guidelines ${ }^{18}$ than their peers attending the European meetings. ${ }^{34}$ Similarly, Kraus et a $\tilde{l}^{\tilde{8}}$ reported in their survey analysis, that German GPs do not consider alcohol intake as a major risk for hypertension ${ }^{58}$ and their screening rates were slightly lower than the European average. ${ }^{58}$ It is arguable that these differences between German and European physicians are due to a stronger cultural bond with alcohol than other European countries, ${ }^{59} 60$ which might obscure the perception of alcohol-related harm among German physicians.

The deficits identified in this study are worth overcoming, as alcohol screening and brief intervention have showed positive results in many European projects. ${ }^{25} 2728$ Lack of resources, training and support from management, as well as workload ${ }^{26}$ have been described as barriers to the adoption of screening and brief intervention. ${ }^{26}$ We believe in the importance of finding economically sustainable ways of working against these barriers with the objective of systematising alcohol interventions. Future research should serve as a valuable feedback measuring the effects and extend of such implementation.

Among the limitations of this study, there might have been a bias towards inclusion of physicians who have a particular interest in the management of hypertension. In addition, reasons for non-participation were not recorded in our study. Also, while we recorded the nationality of the participating physicians, country of practice was not assessed in our survey. During the conduction of the survey, participants who volunteered to participate in the survey were informed by the interviewers before the start of the interview that only one participation was allowed. As participation in the survey was voluntary with anonymised data collection, we cannot exclude the possibility, although deemed very unlikely, of intentional or unintentional multiple participations. The implementation of standardised assessment of alcohol intake, like Alcohol Use Disorders Identification Test for Consumption, ${ }^{61}$ or Severity of Alcohol Dependence Questionnaire ${ }^{62}$ or other available screening instruments, as well as how physicians assess and diagnose alcohol dependence, were not recorded in our study. Furthermore, the majority of physicians participating in the survey were hospital based $(78.5 \%)$, although long-term management of hypertension is predominantly carried out in an ambulatory setting. Moreover, because some questions were formulated as closed questions (ie, questions that can be answered with yes/no) and answers were self-reported, social pressure might have shifted some results upwards and led to an overestimation in our analysis.

In summary, European physicians recognise the high prevalence of comorbid hypertension and harmful alcohol consumption. In addition, some aspects of their management strategies in patients with hypertension regarding alcohol consumption appear adequate. In contrast, alcohol consumption screening in cases of newly detected hypertension, in patients with very high $\mathrm{BP}$, and in treatment-resistant hypertension is very poor. Given the clinical importance of the latter conditions, the current report further supports the notion that improvements of awareness among European physicians on moderation of alcohol intake as an important modifiable lifestyle factor in hypertension management are necessary.

Acknowledgements We are thankful to Angelika Thomas and Rhoda Wismer (signum [ $p r \mathrm{GmbH}$, Cologne) for their excellent support. The survey results were presented at the 27th European Meeting on Hypertension and Cardiovascular Protection 2017 in Milan.

Contributors LZT performed the statistical analyses, interpreted the data and wrote the manuscript. JB supervised the statistical analyses and revised the manuscript. TGR helped perform the statistical analyses with constructive discussion and revised the manuscript. RK conceived and designed the study, revised the manuscript for important intellectual content and provided supervision.

Funding This survey was funded by Lundbeck AS (Valby, Denmark). We acknowledge support from the German Research Foundation (DFG) and the Open Access Publication Fund of Charité-Universitätsmedizin Berlin.

Competing interests None declared.

Patient consent Not required.

Provenance and peer review Not commissioned; externally peer reviewed. Data sharing statement No additional data are available.

Open access This is an open access article distributed in accordance with the Creative Commons Attribution Non Commercial (CC BY-NC 4.0) license, which permits others to distribute, remix, adapt, build upon this work non-commercially, and license their derivative works on different terms, provided the original work is properly cited, appropriate credit is given, any changes made indicated, and the use is non-commercial. See: http://creativecommons.org/licenses/by-nc/4.0/.

\section{REFERENCES}

1. GBD 2016 Risk Factors Collaborators. Global, regional, and national comparative risk assessment of 84 behavioural, environmental and occupational, and metabolic risks or clusters of risks, 1990-2016: a systematic analysis for the Global Burden of Disease Study 2016. Lancet 2017;390:1345-422.

2. NCD Risk Factor Collaboration (NCD-RisC). Worldwide trends in blood pressure from 1975 to 2015: a pooled analysis of 1479 population-based measurement studies with 19.1 million participants. Lancet 2017;389:37-55.

3. Ettehad D, Emdin CA, Kiran A, et al. Blood pressure lowering for prevention of cardiovascular disease and death: a systematic review and meta-analysis. Lancet 2016;387:957-67.

4. Rehm J, Imtiaz S. A narrative review of alcohol consumption as a risk factor for global burden of disease. Subst Abuse Treat Prev Policy 2016;11:37. 
5. Word Health Organization, 2015. Alcohol-Fact sheet from the World Health Organization's Media Centre http://www.who.int/mediacentre/ factsheets/fs349/en/http://www.webcitation.org/6v7UXNd10 (accessed 24 Feb 2017).

6. World Health Organization. Global status report on alcohol and health, 2014

7. Taylor B, Irving HM, Baliunas D, et al. Alcohol and hypertension: gender differences in dose-response relationships determined through systematic review and meta-analysis. Addiction 2009;104:1981-90.

8. Roerecke M, Kaczorowski J, Tobe SW, et al. The effect of a reduction in alcohol consumption on blood pressure: a systematic review and meta-analysis. Lancet Public Health 2017;2:e108-e20.

9. Husain K, Ansari RA, Ferder L. Alcohol-induced hypertension: Mechanism and prevention. World J Cardiol 2014;6:245-52.

10. Zhang X, Abdel-Rahman AA, Wooles WR. Impairment of baroreceptor reflex control of heart rate but not sympathetic efferent discharge by central neuroadministration of ethanol. Hypertension 1989:14:282-92.

11. Abdel-Rahman AA, Wooles WR. Ethanol-induced hypertension involves impairment of baroreceptors. Hypertension 1987;10:67-73.

12. Russ R, Abdel-Rahman AR, Wooles WR. Role of the sympathetic nervous system in ethanol-induced hypertension in rats. Alcohol 1991:8:301-7.

13. Potter JF, Watson RD, Skan W, et al. The pressor and metabolic effects of alcohol in normotensive subjects. Hypertension 1986;8:625-31.

14. Husain K, Vazquez M, Ansari RA, et al. Chronic alcohol-induced oxidative endothelial injury relates to angiotensin II levels in the rat. Mol Cell Biochem 2008;307(1-2):51-8.

15. Wright JW, Morseth SL, Abhold RH, et al. Elevations in plasma angiotensin II with prolonged ethanol treatment in rats. Pharmacol Biochem Behav 1986;24:813-8.

16. Griendling KK, Sorescu D, Ushio-Fukai M. NAD(P)H oxidase: role in cardiovascular biology and disease. Circ Res 2000;86:494-501.

17. Alexander RW. Hypertension and the pathogenesis of atherosclerosis. Hypertension 1995;25:155-61.

18. Mancia G, Fagard R, Narkiewicz K, et al. 2013 ESH/ESC Guidelines for the management of arterial hypertension: the Task Force for the management of arterial hypertension of the European Society of Hypertension (ESH) and of the European Society of Cardiology (ESC). J Hypertens 2013;31:1281-357.

19. Redon J, Mourad JJ, Schmieder RE, et al. Why in 2016 are patients with hypertension not $100 \%$ controlled? A call to action. $J$ Hypertens 2016;34:1480-8.

20. Borghi C, Tubach F, De Backer G, et al. Lack of control of hypertension in primary cardiovascular disease prevention in Europe: Results from the EURIKA study. Int $J$ Cardiol 2016;218:83-8.

21. Wang YR, Alexander GC, Stafford RS. Outpatient hypertension treatment, treatment intensification, and control in Western Europe and the United States. Arch Intern Med 2007;167:141-7.

22. Rehm J, Prieto JA, Beier M, et al. The role of alcohol in the management of hypertension in patients in European primary health care practices - a survey in the largest European Union countries. BMC Fam Pract 2016;17:130.

23. Rehm J, Gmel G, Sierra C, et al. Reduction of mortality following better detection of hypertension and alcohol problems in primary health care in Spain. Adicciones 2018;30:726.

24. Collart F, de Timary P, Dom G, et al. Alcohol-induced hypertension: an important healthcare target in Belgium. Acta Clin Belg 2015;70:389-95.

25. Kaner EFS, Dickinson HO, Beyer FR, et al. Effectiveness of brief alcohol interventions in primary care populations. Cochrane Database Syst Rev 2007;36:Cd004148.

26. Rehm J, Anderson P, Prieto JAA, et al. Towards new recommendations to reduce the burden of alcohol-induced hypertension in the European Union. BMC Med 2017;15:173.

27. PHEPA Network. Primary health care European project on alcohol. http://www.phepa.net/units/phepa/html/en/Du9/index.html. Archived by Webcite at. http://www.webcitation.org/6v7Uvwrtc (accessed 10 Mar 2016).

28. The ODHIN project. (Optimizing delivery of health care interventions) 2011-2014. http://www.odhinproject.eu/. http://www.webcitation.org/ 6V7V52XGF (accessed 24 Feb 2017).

29. Anderson P, Kaner E, Keurhorst M, et al. Attitudes and learning through practice are key to delivering brief interventions for heavy drinking in primary health care: analyses from the odhin five country cluster randomized factorial trial. Int J Environ Res Public Health 2017; $14: 121$.
30. German Society of Cardiology. DGK Düsseldorf. https://dgk.org/. Archived by Webcite at. http://www.webcitation.org/6v8VsEMT1 (accessed 10 March 2016).

31. German Society of Internal Medicine. DGIM Wiesbaden. http:// www.dgim.de/. Archived by Webcite at. http://www.webcitation.org/ 6v8wocemO (accessed 10 March 2016).

32. European Society of Hypertension. ESH Europe. http://www. eshonline.org/. Archived by Webcite at. http://www.webcitation.org/ 6v8wyBSdH (accessed 10 Mar 2016).

33. European Society of Cardiology. ESC Europe. https://www.escardio. org/. Archived by Webcite at. http://www.webcitation.org/6v8x6BPT3 (accessed 10 Mar 2016)

34. Bolbrinker J, Zaidi Touis L, Gohlke H, et al. European guidelines on lifestyle changes for management of hypertension : Awareness and implementation of recommendations among German and European physicians. Herz 2018;43.

35. Alcohol Guidelines Review. Report from the Guidelines development group to the UK Chief Medical Officers. 44, 2016.

36. Forouzanfar MH, Alexander L, Anderson HR, et al. Global, regional, and national comparative risk assessment of 79 behavioural, environmental and occupational, and metabolic risks or clusters of risks in 188 countries, 1990-2013: a systematic analysis for the Global Burden of Disease Study 2013. The Lancet 2015;386:2287-323.

37. Williamson W, Foster $\mathrm{C}$, Reid $\mathrm{H}$, et al. Will exercise advice be sufficient for treatment of young adults with prehypertension and hypertension? a systematic review and meta-analysis. Hypertension 2016;68:78-87.

38. Siebenhofer A, Jeitler K, Horvath K, et al. Long-term effects of weight-reducing drugs in people with hypertension. Cochrane Database Syst Rev 2016;3:Cd007654.

39. Elmer PJ, Obarzanek E, Vollmer WM, et al. Effects of comprehensive lifestyle modification on diet, weight, physical fitness, and blood pressure control: 18-month results of a randomized trial. Ann Intern Med 2006;144:485-95.

40. The treatment of mild hypertension study. A randomized, placebocontrolled trial of a nutritional-hygienic regimen along with various drug monotherapies. The Treatment of Mild Hypertension Research Group. Arch Intern Med 1991;151:1413-23.

41. Frisoli TM, Schmieder RE, Grodzicki T, et al. Beyond salt: lifestyle modifications and blood pressure. Eur Heart J 2011;32:3081-7.

42. Allamani A, Voller F, Decarli A, et al. Contextual determinants of alcohol consumption changes and preventive alcohol policies: a 12-country European study in progress. Subst Use Misuse 2011;46:1288-303.

43. Norström T, Simpura J, Ö H, et al. Conclusions: Alcohol in postwar Europe: consumption, drinking patterns, consequences and policy responses in 15 European countries: Almqvist\&Wiksell, 2002:185-94.

44. GAPA (Global Alcohol Policy Alliance). http://globalgapa.org/index. php/about-us/. Archived by Webcite at. http://www.webcitation.org/ 6v8wbf9GA (accessed 24 feb 2017).

45. AMPHORA. Project description-The European Alcohol Policy Research Alliance. 2010 http://www.amphoraproject.net/view.php? id_cont=46\&PHPSESSID=ecp57e414c2gc4c7bhaflt3i62 Archived by Webcite at. http://www.webcitation.org/6v7VN9xDY (accessed 24 Apr 2017).

46. European Commission. Alcohol Measures for Public Health Research Alliance (AMPHORA): EU Publications Office, 2009. Available fromArchived by Webcite at. http://cordis.europa.eu/project/rcn/ 92876_en.htmlhttp://www.webcitation.org/6v8wDS9Zt. (accessed 24 Apr 2017).

47. AMPHORA. Final Report Summary - AMPHORA (Alcohol Measures for Public Health Research Alliance): European Commission, 2013.

48. Rehm J, Shield K, Rehm M, et al; Alcohol consumption, alcohol dependence, and attributable burden of disease in Europe: Potential gains from effective interventions for alcohol dependence, 2012.

49. Cai A, Calhoun DA. Resistant hypertension: an update of experimental and clinical findings. Hypertension 2017;70:5-9.

50. Sim JJ, Bhandari SK, Shi J, et al. Characteristics of resistant hypertension in a large, ethnically diverse hypertension population of an integrated health system. Mayo Clin Proc 2013;88:1099-107.

51. Sim JJ, Bhandari SK, Shi J, et al. Comparative risk of renal, cardiovascular, and mortality outcomes in controlled, uncontrolled resistant, and nonresistant hypertension. Kidney Int 2015;88:622-32.

52. Muntner P, Davis BR, Cushman WC, et al. Treatment-resistant hypertension and the incidence of cardiovascular disease and end-stage renal disease: results from the Antihypertensive and Lipid-Lowering Treatment to Prevent Heart Attack Trial (ALLHAT). Hypertension 2014;64:1012-21. 
53. Daugherty SL, Powers JD, Magid DJ, et al. Incidence and prognosis of resistant hypertension in hypertensive patients. Circulation 2012;125:1635-42.

54. de Beus E, Bots ML, van Zuilen AD, et al. Prevalence of apparent therapy-resistant hypertension and its effect on outcome in patients with chronic kidney disease. Hypertension 2015;66:998-1005.

55. Diaz KM, Booth JN, Calhoun DA, et al. Healthy lifestyle factors and risk of cardiovascular events and mortality in treatment-resistant hypertension: the reasons for geographic and racial differences in stroke study. Hypertension 2014;64:465-71.

56. Shimbo D, Levitan EB, Booth JN, et al. The contributions of unhealthy lifestyle factors to apparent resistant hypertension: findings from the Reasons for Geographic And Racial Differences in Stroke (REGARDS) study. J Hypertens 2013;31:370-6.
57. Sarafidis PA, Georgianos P, Bakris GL. Resistant hypertension--its identification and epidemiology. Nat Rev Nephrol 2013;9:51-8.

58. Kraus L, Schulte B, Manthey J, et al. Alcohol screening and alcohol interventions among patients with hypertension in primary health care: an empirical survey of German general practitioners. Addict Res Theory 2017;25:285-92.

59. Anderson LMaGG P. Alcohol in the European Union. Consumption, harm and policy approaches: World Health Organization, 2012.

60. Karlsson T, Simpura J. Changes in living conditions and their links to alcohol consumption and drinking patterns in 16 European countries, 1950 to 2000. Nordic Studies on Alcohol and Drugs 2001;18:82-99.

61. WHO. AUDIT: The Alcohol Use Disorders Identification Test: WHO.

62. Edwards G, Gross MM, Keller M, et al. Alcohol related disabilities WHO, 1977. 